\title{
Comprehension and Motivation of ESL Learners: Basis for a Reading Intervention Plan
}

\author{
Danica N. Marcelo ${ }^{1,2, *}$, Jennifer P. Santillan² \\ ${ }^{1}$ College of Education, Pampanga State Agricultural University, Philippines \\ ${ }^{2}$ Graduate School, Angeles University Foundation, Philippines
}

Received June 21, 2020; Revised August 31, 2020; Accepted September 11, 2020

\begin{abstract}
Cite This Paper in the following Citation Styles
(a): [1] Danica N. Marcelo, Jennifer P. Santillan, "Comprehension and Motivation of ESL Learners: Basis for a Reading Intervention Plan," Universal Journal of Educational Research, Vol. 8, No. 11, pp. 5197-5202, 2020. DOI: 10.13189/ujer.2020.081120.
\end{abstract}

(b): Danica N. Marcelo, Jennifer P. Santillan (2020). Comprehension and Motivation of ESL Learners: Basis for a Reading Intervention Plan. Universal Journal of Educational Research, 8(11), 5197-5202. DOI: 10.13189/ujer.2020.081120.

Copyright $\odot 2020$ by authors, all rights reserved. Authors agree that this article remains permanently open access under the terms of the Creative Commons Attribution License 4.0 International License

\begin{abstract}
This quantitative descriptive study investigated the reading motivation and performance of randomly selected 300 English as second language (ESL) learners at three levels of comprehension. The Revised Motivation for Reading Questionnaire (MRQ) and the researchers-made comprehension test were used as instruments to identify the respondents' motivation and performance in literal, inferential, and evaluative levels. Based on the results of the MRQ, more than half of the respondents are extrinsically motivated. Moreover, they are likely to be motivated if they are interested in what they read and when they receive grades and recognition while reading. On the contrary, they are least motivated to read for social purposes. On their reading comprehension, results reveal that respondents performed satisfactorily in the literal level and fairly in inferential and evaluative levels. These findings are the bases of the reading intervention plan that contains (I) objectives, (II) time frame, (III) suggested reading material, (IV) strategy, (V) activity, and (VI) resources. Further, implications for teaching reading are included in the study.
\end{abstract}

Keywords Intrinsic, Extrinsic, Reading Motivation, Reading Comprehension

\section{Introduction}

The ability to read and the ability to comprehend are two different things. Comprehension comes with understanding a text. In the Philippines, there are 20.1 million people aged 10 to 64 years old, who cannot even comprehend what they read based on Functional Literacy, Education, and Mass Media Survey. This figure is quite alarming as it suggests inadequacy in the capability of Filipino readers as far as comprehension skill is concerned [1].

Looking at a deeper context, the low comprehension rate may be the effect of the usual problems in the areas of reading. Also, the problems lie in the learners' lack of love for reading. This concern is due to few or no programs that would encourage the students to love reading. In the local scenario, some educators lack the skills in teaching, and it is worsened because administrators do not invest much in training teachers to teach reading [2].

To aid the students in the problems they encounter in reading, there are proposed strategies that are taught and practiced in schools. However, strategies would not be successful if learners lack the drive to read. Too often, students prefer other activities to reading. What is saddening is the fact that motivation contributes to text comprehension. More specifically, motivation increases the reading amount of and spurs frequent, effortful reading [3]. Meanwhile, improved comprehension has positive effects on motivation [4].

It is also believed that reading motivation is positively associated with reading comprehension. However, proving the relationship between reading motivation and reading comprehension is not adequate to help learners improve. Therefore, teachers must have a plan or structured intervention to ensure all students have the best chance to 
grow as motivated readers for teachers' influence on students' motivation is too important to ignore [5].

Evidence suggests that reading interventions with adolescents can be effective [6]. This fact is also affirmed by other researchers who noted that contrary to the expectation that secondary level students are proficient readers, these learners need to be guided by effective methods of teaching reading and be taught effective instructional tools that meet their needs [7]. The need to examine the reading motivation and the performance of learners in standardized testing is also emphasized [8].

Moreover, since reading comprehension may break down at many points for the complex processes it involves, creating an intervention plan with multifaceted approaches may not be effective. Thus, it is suggested that the intervention plan must match the objectives to the needs of the students [9].

One of the key targets that an intervention plan may focus on is the selection of the reading materials. Filipino teachers think that what they provide their students are texts which the latter are interested in. However, they may fall short in assessing whether the topics of the reading materials are engaging for the learners. In addition, it is noticeable that only a few reading activities promote collaboration or are fun and competitive. When students become less motivated or unmotivated, their performance becomes lower as well [10].

With the number of learners who perform poorly in comprehension and with less motivation they have in reading as cited above, the researchers came up with a study that aimed to know the motivation of learners and their performance in reading at different levels. This study served as the basis in creating an intervention plan that would serve as a guide for teachers in designing their reading activities. This study particularly sought to improve learners' motivation and reading comprehension performance.

\section{Objective of the Study}

Generally, the researchers wanted to know the intrinsic and extrinsic motivation and the performance of the respondents in three reading levels to be able to propose a reading intervention plan that addresses the students' needs. Specifically, this study aimed to (1) describe the motivation of the respondents in reading in terms of intrinsic and extrinsic; (2) describe the respondents' reading comprehension in terms of the levels (a) literal, (b) inferential, and (c) evaluative; (3) propose a reading intervention plan based on the respondents' comprehension and motivation results; and (4) identify the implications of the findings for the teaching of reading.

\section{Methods}

\section{Research Design}

The researchers used a quantitative type of research. This method of research involves the present phenomena in terms of conditions, practices, beliefs, and relationships. Specifically, the descriptive design helped the researchers identify the type of motivation of the respondents and assess their reading comprehension in three levels. Moreover, the design covers proper analyses of the components of intrinsic and extrinsic motivation and the levels of reading comprehension, interpretation and the comparisons of gathered data, and identification of the needs of students crucial to the design of the reading intervention plan [11].

\section{Respondents}

A total of 300 high school freshmen from both public and private schools enrolled in the school year 2016 to 2017participated in the study. Freshmen were chosen because they are ESL learners and were enrolled in a Literature class giving them regular exposure to reading and comprehension test. Based on the total number of grade 7 students in the seven participating schools, the researchers determined the sample size by using Raosoft,com, an online calculator. Each school was represented by one section identified through the lottery method.

\section{Research Instruments}

\section{Measure for Motivation}

The researchers used the revised version of Motivation for Reading Questionnaire (MRQ) [4] with the reliability (alpha) of 0.59 to 0.88 to assess the participants' motivation in reading. However, the study only used eight out of 11 scales or components of the original MRQ namely curiosity (six items), involvement (six items), preference for challenge (five items), recognition (five items), grades (four items), social (seven items), competition (six items), and compliance (four items). These identified eight scales or components fall under intrinsic and extrinsic motivation. The respondents had four options, 1 to 4 with verbal interpretation ranging from very different from me to a lot like me [4].

\section{Measure for Reading Comprehension}

Three levels of comprehension (literal, inferential, and evaluative) of the respondents were measured using the researchers-made reading comprehension test. The test consisted of three Filipino stories titled The Story of the First Durian, The Legend of the Dama de Noche, and The Story of Alunsina and Tungkung Langit. For each legend, there were 10 multiple-choice questions worth one point 
each. The stories were Philippine literature pieces aligned with the curriculum of the learners. English teachers validated the literary pieces and the comprehension test as to appropriateness, accuracy, clarity, etc. Minor revisions were made based on the validation done.

\section{Data Analysis}

The data were analyzed using descriptive statistics. Specifically, the researchers used (a) mean to compute the average of each of the scale in the MRQ and the average scores of the respondents in the reading comprehension test; (b) Frequency distribution to group the raw scores of the respondents into categories; and (c) percentage to compare the values and data collected in the study.

\section{Procedures}

The researchers obtained the necessary permission and informed and parental consent. During the data collection, the respondents answered MRQ for 20 minutes. Then, they read the selection one at a time and later answered the corresponding comprehension test for 40 to 50 minutes.

\section{Results and Discussion}

Table 1 shows that more respondents are extrinsically motivated than intrinsically motivated. This result means that their motivation in reading comes from external factors. However, there is only a slight difference between the mean scores of the types of the motivation of the respondents which may indicate that the respondents' drive to read may be a combination of intrinsic and extrinsic motivation. Thus, activities that would target these motivations may be suggested. It is also important to consider the trends of changing motivations when designing an intervention plan. Based on relevant findings, the high proficiency group tends to have an increased intrinsic motivation; whereas, the low proficiency group shows an increased extrinsic motivation when subjected to an intervention [12].

Table 1. Respondents' motivation

\begin{tabular}{|c|c|c|c|c|c|c|}
\hline \multirow{2}{*}{ Respondents } & \multicolumn{3}{|c|}{ Intrinsic } & \multicolumn{3}{c|}{ Extrinsic } \\
\cline { 2 - 7 } & $f$ & $\%$ & $\mathrm{~m}$ & $f$ & $\%$ & $\mathrm{M}$ \\
\hline $\mathrm{N}=300$ & 136 & 45.33 & 3.11 & 164 & 54.7 & 3.15 \\
\hline
\end{tabular}

Table 2 reveals that among the components, grades, a component of extrinsic motivation got the highest mean score $(M=3.41)$. This finding means that most of the respondents are highly motivated when grades are involved in their reading tasks. Grades is followed by recognition $(\mathrm{M}=3.33)$ and compliance $(\mathrm{M}=3.25)$ which are both components of extrinsic motivation. Meanwhile, curiosity $(\mathrm{M}=3.19)$ dominated those under intrinsic motivation, which means that learners become motivated when they find the reading material and discussion interesting.

Additionally, the figures tell that respondents are least motivated when there is competition $(\mathrm{M}=2.92)$. Also, they do not find it motivating when they share their reading experience with their parents, relatives, or even friends $(\mathrm{M}=2.86)$.

Table 2. Mean scores of the components of intrinsic and extrinsic motivation

\begin{tabular}{|l|c|c|}
\hline Intrinsic Motivation & Mean & Interpretation \\
\hline Curiosity & 3.19 & A little like me \\
\hline Involvement & 3.06 & A little like me \\
\hline Preference for Challenge & 3.09 & A little like me \\
\hline Extrinsic Motivation & & \\
\hline Recognition & 3.33 & A little like me \\
\hline Grades & 3.41 & A little like me \\
\hline Social & 2.86 & A little like me \\
\hline Competition & 2.92 & A little like me \\
\hline Compliance & 3.25 & A little like me \\
\hline
\end{tabular}

Similar with these findings, grades and curiosity are found to be motivating factors among learners in the second language (L2) reading in the Filipino secondary school classroom. First, grades appear to be a goal established prior to reading. Learners consider these as a basis on how well they do in L2 reading [10]. However, other researchers $[13,14]$ warn that grades may not be used as motivators to all students, particularly the low-achieving ones. Second, curiosity is seen to be a vital construct in reading as it broadens the learners' knowledge about topics and ideas they are interested in [15]. Hence, choosing a material is an aspect that makes a difference to $\mathrm{L} 2$ reading motivation. As was also found in other studies, a broad range of easy and interesting reading materials are key to motivating less motivated students $[12,16]$. In contrast to these most motivating factors, social purposes are the least among the learners' list of reasons for reading [10]. Such consistent findings in the Philippine setting may have something to do with the Filipino culture, in which reading is not an activity shared with relatives and rarely with friends. Also, libraries are not usually found in small towns.

Table 3 shows the performance of the respondents in three levels of comprehension. Most of the respondents having the mean of 6.64 performed satisfactorily in the literal level, while they performed fairly in the inferential and evaluative levels with the mean scores of 4.99 and 4.67, respectively. Generally, most of the respondents performed well in the literal level comprehension test. Since not even half of them got the rating Very Satisfactory, researchers acknowledge that there is still a need to enrich students' skills. The respondents gained lower scores on the inferential and evaluative levels, which is congruent with 
the study about examining the inferring abilities of the 8th grade ESL learners [17]. In this cited study, those who comprehended the texts performed significantly lower in answering questions concerning information which are not explicitly stated in the text. This implies that more activities should be administered to improve the inferential and evaluative levels of the learners [17].

Table 3. Mean scores of the levels of comprehension

\begin{tabular}{|l|c|c|}
\hline Levels of Comprehension & M & DR \\
\hline Literal & 6.64 & Satisfactory \\
\hline Inferential & 4.99 & Fair \\
\hline Evaluative & 4.67 & Fair \\
\hline
\end{tabular}

\section{Proposed intervention plan}

Since a number of respondents scored low in the literal, inferential, and evaluative levels, the researchers decided to design an intervention plan that will tackle all three levels of comprehension. Though a majority of the respondents classified all the components of both intrinsic and extrinsic motivation "a little like them," the researchers designed an intervention plan tapping only the components that got the low mean scores.

\section{Content}

The intervention plan contains (I) objectives, (II) time frame, (III) suggested reading material, (IV) strategy, (V) activity, and (VI) resources based on the template for intervention plan of the Department of Education, Philippines.

\section{Objectives}

The researchers specified the target reading level and the target components of intrinsic and extrinsic motivation. The components that got the low scores are emphasized in the hope that they would be significant factors in increasing the learners' reading comprehension.

\section{Time frame}

Time frame indicates the duration of the activities. The time allotment for each proposed reading activity is usually 15 to 20 . Seventeen minutes per day of reading intervention is needed to close the gap and accelerate academic achievement [18]. The suggested reading material includes the possible reading texts that can be used for enrichment. These generally-described suggested texts can be modified according to the needs encountered in every lesson. However, it is advised to use brief selections as "reading a few could be just what someone needs to get motivated to read a regular-length selection" [19]. These materials are narrative and expository in nature.

\section{Strategies}

These are based on methods from which the activities are anchored. These are chosen to specifically aid the learners in improving their reading motivation and reading comprehension. The strategies used in the literal level are (1) read aloud, (2) retelling, (3) summarizing, and (4) questioning. Under the same column are other micro-strategies such as (1) visualization, (2) imagination, (3) mental imagery, (4) inference, and (5) predicting all aiming to develop the inferential level. Lastly, the strategies for the evaluative level are (1) reciprocal questioning and (2) close reading. All reading levels are targeted because they are complementary to one another. There are fewer in the evaluative level because these can be modified and repeated.

\section{Activities}

The activities in the proposed plan are tasks which are based on the strategies and are used to improve the literal, inferential, and evaluative comprehension of the respondents as well as the components of intrinsic and extrinsic motivation. Focused on enriching the literal level using the strategy read aloud, the researchers chose the activities (1) story mapping and (2) Wh-Wheel; for retelling and summarizing, the activity is scrambled stories. For questioning, the activity is Chalk Up! The strategies used in the literal level were already found to be effective by other researchers. In the study "Analyzing the Effects of Story Mapping on the Reading Comprehension of Children with Low Intellectual Abilities," story mapping was beneficial in improving the reading comprehension of struggling learners [20]. Likewise, the findings suggest that retelling is an effective reading strategy [21]. It was also emphasized that questioning develops interest and motivates students to become actively involved in lessons. Furthermore, the activities chosen complement the strategies and can be a tool in achieving the target motivation and level of comprehension [22].

Additionally, aiming to enhance the inferential level using the strategies visualization, imagination, and mental imagery, the researchers chose the activities (1) Character Impressions and (2) Word of Mouth; for the Inference, the activities are (1) The "Y" of Why's, (2) Open Portraits, (3) Claim-Evidence-Reason and (4) Staging a Crime Scene: for Predicting, the activity is (1) Tell me your "A". The strategies used in the inferential level were also supported by different researchers and authors. Visualizing is effective for readers to use images to draw conclusions and unique interpretations of the text [23]. In addition, based on the book "Reading Strategies-Inference," using inference as a strategy in reading results in enhanced understanding and increased learning and retention. Moreover, when learners read inferentially, they utilize higher thinking levels, such as drawing conclusions in response to what they are reading [24].

Another strategy used is predicting. Predicting makes connections between prior knowledge and text, thus activating a higher thinking level. Since the current study reveals that learners scored lower in the inferential level, 
the researchers chose activities that are anchored on strategies that tap lower order thinking skills and activate higher thinking level. Also, these activities have characteristics that would engage learners in interaction and collaboration such as games. This intervention plan also aims to make the learners competitive and socially active that is assumed to be beneficial in improving their motivation and reading motivation [25].

Next, targeting the evaluative level using reciprocal questioning, the researchers chose the activity Carousel Talk; for close reading, the activities are (1) Think Win-Win, (2) Round-Table Discussion, and (3) If You Give a Mouse a Cookie. Specific instructions for the activities are provided. However, a teacher may change the way s/he wants to implement the activities as long as the concept and the goals of the activity are attained.

The strategies used in the evaluative level were also supported by different researchers and authors. Evidence of the effectiveness of Reciprocal Questioning (ReQuest) strategy was seen in the study "The Use of Reciprocal Questioning Strategy in teaching Reading Comprehension." Based on the findings of the study, the respondents performed better in their reading comprehension when ReQuest was used as an intervention. By implementing such a strategy, students would no longer consider reading as a frustrating activity that causes boredom [26].

Also, the practice of close reading was found to be motivating [6]. This strategy requires a student to read the text multiple times to strengthen understanding. Aside from these strategies, the activities in the plan were also evaluated through different studies. Research suggests that the Round Table is a successful learning technique for students as it promotes an informal teaching approach that makes students comfortable in the classroom setting. Moreover, Carousel Talk provides scaffolding for new ideas to be learned through movement, conversation, and reflection. Since there are only a few activities for the evaluative level, these activities can be used alternately.

Because the current study reveals that respondents scored lower in the evaluative level, the researchers chose activities that are anchored on strategies that activate higher order thinking level. Also, these have characteristics that would engage learners such as Round-Table and Carousel Talk. Also, in this part of the intervention plan, learners are encouraged to discern and argue with another team for them to evaluate, come up with adequate evidence, and defend and refute ideas. Integrating curiosity, recognition, and grades, the researchers designed these activities.

\section{Resources}

This section indicates the materials that are needed in implementing the activities. They fall under traditional and non-traditional instructional materials.

\section{Implications of the Study}

Based on the data collected, reading instruction should be improved to enhance the motivation and comprehension of learners. This can be done through the use of research-based strategies and activities to improve their levels of comprehension and both intrinsic and extrinsic motivations. Also, there is a need to capitalize on the interest of learners and to establish a more challenging and collaborative classroom setting and home environment.

\section{Conclusions}

Teachers must give reading activities that are curiosity, inducing challenging and participatory. They must also allow students to interact with their classmates, compete with them, comply with instructions, and earn grades and recognition when reading to be better engaged. Also, they should provide reading activities targeting literal, inferential, and evaluative levels of reading. Future researchers may conduct a similar study that would involve students in intermediate level as respondents, a different reading motivation measure, and a standardized reading comprehension test or another teacher-made and validated one to be subjected to pilot testing and measured in terms of reliability.

\section{REFERENCES}

[1] G. Nolasco. Multilingual Philippines. Retrieved from https://mlephil.wordpress.com/2010/10/02/20m-filipinos-ca n-read-but-cannot-understand/. 2010

[2] G. Lee. Reading in the Philippines. Literacy Today (2411-7862), 33(1), 32-34. 2015.

[3] R. Capen. The Role of the Teacher and Classroom Environment in Reading Motivation. Illinois Reading Council Journal, 38(4), 20-25. 2010.

[4] A. Wigfield \& J.T. Guthrie. Relations of children's motivation for reading to the amount and breadth of their reading. Journal of Educational Psychology. 89, 430-432.1. 1997.

[5] V. Clinton. Examining Associations Between Reading Motivation and Inference Generation Beyond Reading Comprehension Skill. Reading Psychology, 36(6), 473-498. doi:10.1080/02702711.2014.892040. 2015.

[6] D. Fisher \& N. Frey. Close Reading as an Intervention for Struggling Middle School Readers. Journal Of Adolescent \& Adult Literacy, 57(5), 367-376. doi:10.1002/jaal.266. 2014.

[7] L. M. Joseph \& R. Schisler. Should adolescents go back to the basics? A review of teaching word reading skills to middle and high school students. Remedial Spec. Educ. 30, 131-148. doi: 10.1177/0741932508315646. 2009.

[8] W. Mucherah \& A. Herendeen. Motivation for Reading and Upper Primary School Students' Academic Achievement in Reading in Kenya. Reading Psychology, 34(6), 569-593. 
doi:10.1080/02702711.2012.664249. 2013.

[9] T. O'Reilly, J. Weeks, J. Sabatini, L. Halderman, \& J. Steinberg. Designing Reading Comprehension Assessments for Reading Interventions: How a Theoretically Motivated Assessment Can Serve as an Outcome Measure. Educational Psychology Review, 26(3), 403-424.doi:10.1007/s10648-01 4-9269-. 2014

[10] A. Cirocki \& J. Caparoso, J. Attitudes, Motivations and Beliefs about L2 Reading in the Filipino Secondary School Classroom: A Mixed- methods Study. International Journal of Applied Linguistics \& English Literature, 5 (7):1-18. 2016.

[11] N. Salaria. Meaning of the Term Descriptive Survey Research Method. International Journal of Transformations in Business Management, 1(6), 1-7. 2012.

[12] J. Briggs \& C. Walter. Read on! Extensive Reading and Young Second Language Learners' Motivation and Attitudes. Oxford University Press. 2016

[13] D. S. Kaplan, B. M. Peck, \& H. B. Kaplan. Decomposing the academic failure-dropout relationship: A longitudinal analysis. Journal of Educational Research, 90, 331-343. 1997.

[14] A. Woolfolk, \& K. Margetts. Educational psychology (3rd ed.). Frenchs Forest: Pearson Australia. 2013.

[15] A. Cirocki. Developing learner autonomy through tasks: Theory, research, practice. Halifax: LinguaBooks. 2016.

[16] A. Takase. The effects of extensive reading on the motivation of Japanese high school students. Unpublished doctoral dissertation. Temple University, Japan. 2003.

[17] H.W. Catts, S. M. Adlof \& S. E. Weismer. Language Deficits in Poor Comprehenders: A Case for the Simple View of Reading. Journal of Speech, Language, and
Hearing Research, 49: 278-293. 2006.

[18] L. Fielding, N. Kerr, \& P. Rosier. Annual growth for all students, catch up growth for those who are behind. Kennewick, WA: The New Foundation Press, Inc. 2007.

[19] H. Jacobson. How many of us still read a book in bed? Retrieved from http://www.the.guardian.com/books/2017. 2017.

[20] M. Grunke, J. Wilbert \& K. C. Stegemann. Analyzing the Effects of Story Mapping on the Reading Comprehension of Children with Low Intellectual Abilities. Learning Disabilities: A Contemporary Journal 11(2), 51-64. 2013.

[21] Han. Retelling as an effective reading comprehension strategy for young ESL learners. Retrospective Theses and Dissertations. Retrieved from http://lib.dr.iastate.edu/rtd/16 269. 2005.

[22] K. Cotton. Classroom questioning. School Improvement Research Series. Northwest Regional Educational Laboratory. Retrieved from http://www.nwrel.org/scpd/sirs/ 3/cu5.html. 1989.

[23] D. Draper. Comprehension Strategies. Retrieved from https://www.google.com.ph. 2012.

[24] Don Johnston, Inc. Reading Strategies - Inference. Retrieved from http://www.icam.k12.in.us/DJ/Materials/_S upport_Materials/InferenceLessonInstructions.pdf. 2009.

[25] Gaither. Making Predictions: A Strategy for Reading and Science Learning. Retrieved from http://beyondweather.ehe .osu.edu/issue/the-sun-and-earthsclimate/making-predictions-a-strategy-for-reading-and-scie nce-learning. 2011.

[26] Yuniarti \& Bambang. The Use of Reciprocal Questioning Strategy in teaching Reading Comprehension. Retrieved from portalgaruda.org/article.com. 2014. 